\title{
Characterization of Candidate Materials for Remote Recession Measurements of Ablative Heat Shield Materials
}

\author{
Bradley D. Butler ${ }^{*}$, Michael Winter ${ }^{\dagger}$, Francesco Panerai ${ }^{\ddagger}$, \\ Alexandre Martin ${ }^{\S}$, Sean C.C. Bailey ${ }^{* *}$ \\ University of Kentucky, Department of Mechanical Engineering, Lexington, KY 40506-0503, USA \\ Margaret Stackpoole ${ }^{\dagger \dagger}$ \\ NASA Ames Research Center, Moffett Field, CA 94035-1000, USA \\ Paul M. Danehy ${ }^{\star \star}$, Scott Splinter $\$ \S$ \\ NASA Langley Research Center, Hampton, VA 23681-2199, USA
}

\begin{abstract}
A method of remotely measuring surface recession of a material sample in a plasma flow through emission spectroscopy of the post shock layer was characterized through experiments in the NASA Langley HYMETS arcjet facility. Different methods for delivering the seed products into the Phenolic Impregnated Carbon Ablator (PICA) material samples were investigated. Three samples were produced by seeding the PICA material with combinations of $\mathrm{Al}, \mathrm{Si}, \mathrm{HfO}_{2}, \mathrm{VB}_{2}, \mathrm{Al}_{2} \mathrm{O}_{3}, \mathrm{SiO}_{2}$, TiC, $\mathrm{HfC}, \mathrm{NaCl}$, and $\mathrm{MgCl}_{2}$ through infusing seed materials into a core of PICA, or through encapsulating seed material in an epoxy disk, mechanically bonding the disk to a PICA sample. The PICA samples seeded with the candidate tracers were then tested at surface temperatures near $2400 \mathrm{~K}$ under low pressure air plasma. The emission of $\mathrm{Al}, \mathrm{Ti}, \mathrm{V}, \mathrm{Na}$, and $\mathrm{Mg}$ in the post-shock layer was observed in the UV with a high resolution imaging spectrometer viewing the whole stagnation line from the side, and from UV to NIR with a fiber-coupled miniaturized spectrometer observing the sample surface in the wavelength range from $200 \mathrm{~nm}$ to $1,100 \mathrm{~nm}$ from the front through a collimator. $\mathrm{Al}, \mathrm{Na}$, and $\mathrm{Mg}$ were found to be emitting in the post-shock spectra even before the recession reached the seeding depth - therefore possibly characterizing the pyrolysis process rather than the recession itself. The appearance of $\mathrm{Ti}$ and $\mathrm{V}$ emission in the spectra was well correlated with the actual recession which was monitored through a video of the front surface of the sample. The applicability of a seed material as an indicator for recession appears to be related to the melting temperature of the seed material. Future parametric studies will be carried out in low power plasma facilities at the University of Kentucky.
\end{abstract}

\footnotetext{
* PhD candidate, Department of Mechanical Engineering, 151 Ralph G. Anderson Building, Lexington, KY 40506-0503, USA, student member AIAA.

$\dagger$ Assistant Professor, Department of Mechanical Engineering, 185 Ralph G. Anderson Building, Lexington, KY-40506-0503, USA, Associate Fellow AIAA.

¥ Research Fellow, Department of Mechanical Engineering, NASA Visiting Scientist, Thermal Protection, Materials Branch, member AIAA.

$\S$ Assistant Professor, Department of Mechanical Engineering, 261 Ralph G. Anderson Building, Lexington, KY-40506-0503, USA, Associate Fellow AIAA.

** Associate Professor, Department of Mechanical Engineering, 283 Ralph G. Anderson Building, Lexington, KY-40506-0503, USA, member AIAA.

${ }^{\dagger}$ Senior Research Scientist, Thermal Protection Materials and Systems Branch, NASA Ames Research Center,

$\$$ Research Scientist, Advanced Measurements and Data Systems Branch, MS 493. Associate Fellow AIAA.

$\S \S$ Aerospace Engineer, Structural Mechanics and Concepts Branch, M/S 190, AIAA Member.
}

1

American Institute of Aeronautics and Astronautics 


\section{Introduction and Motivation}

SPACECRAFT entering into a planet's atmosphere experience significant heat loads while the kinetic energy is dissipated during the slowing down of the vehicle. To protect the spacecraft, thermal protection systems (TPS) are needed. TPS can be divided in two categories: for lower entry speeds such as return from low earth orbit, radiative cooling may be sufficient and re-useable materials such as high temperature ceramics deliver sufficient performance. For higher entry speeds as experienced for re-entries from interplanetary missions, ablative materials are needed which thermally and mechanically decompose during the hot re-entry phase therefore dissipating additional energy to the surrounding gas.

The development of reliable TPS for atmospheric entries requires extensive material testing in ground test facilities under conditions relevant to high speed re-entry such as the NASA Ames arcjets. However, even these high power facilities are not capable of reproducing real flight conditions. Instead, an extrapolation of the ground test data to atmospheric entry conditions is necessary. This is achieved through aerothermochemistry simulation codes. Thus, aerothermochemistry and material response simulations have become the most important tool for designing new TPS systems.

Material recession and charring are two major processes determining the performance of ablative heat shield materials. For recession measurements during ground testing, optical methods such as imaging the sample surface during testing are under investigation ${ }^{1}$ but require high alignment and instrumentation effort, therefore being not yet established as a standard measurement method. Typically, the characterization of recession relies widely on measurements of material thickness before and after testing, thus providing only information integrated over the test time. For char depth measurements, the most common method so far consists in investigation of sectioned samples after testing or in the case of capsule reentries such as Stardust where core extractions were performed to determine char information. ${ }^{2}$ In flight, no reliable recession measurements are available, except total recession after recovering the heat shield on ground. Developments of electro-mechanical recession sensors have been started ${ }^{3}$ but require $^{2}$ substantial on board instrumentation adding mass and complexity. Motivated by the detection of tracer elements such as sodium, potassium, magnesium, and calcium in spectrally resolved data gathered during the airborne observation campaign of the Stardust sample return capsule, ${ }^{4}$ a methodology for recession measurements through the detection of seed elements buried at known depths inside the TPS material was developed. A feasibility study in a NASA Ames arcjet facility was successfully conducted and showed promising results. ${ }^{5}$ Applications besides ground testing are recession and possibly char depth measurements during actual re-entry. Detection through emission spectroscopy could be accomplished through ground based or airborne observation as performed during the Stardust ${ }^{4}$ and Hayabusa ${ }^{6}$ re-entries, through on-board spectrometers, or even through formation flight. However, an application of remote recession measurements to real missions requires further tests under controlled conditions to down-select the optimum seed materials and quantify the amounts needed and the achievable accuracy through this method before being proposed for a NASA mission.

The basic idea of remote recession sensing is to seed specific materials at a known depth inside the ablative material. Once recession reaches the seeding depth, the seed material comes in contact with the plasma, is gasified, and transported into the hot region of the postshock layer by diffusion processes where the characteristic emission signatures can be detected by emission spectroscopy. The working principle is illustrated in Fig. 1. For detection, no spatial resolution of the optical system is needed as confirmed during the feasibility demonstration experiments at NASA Ames. ${ }^{5}$ Spatial resolution through the thickness of the heat shield material, however, is achieved through a local deposition of the seed material in the TPS. The emission of the seed elements is then observed through external observation of the post shock plasma.
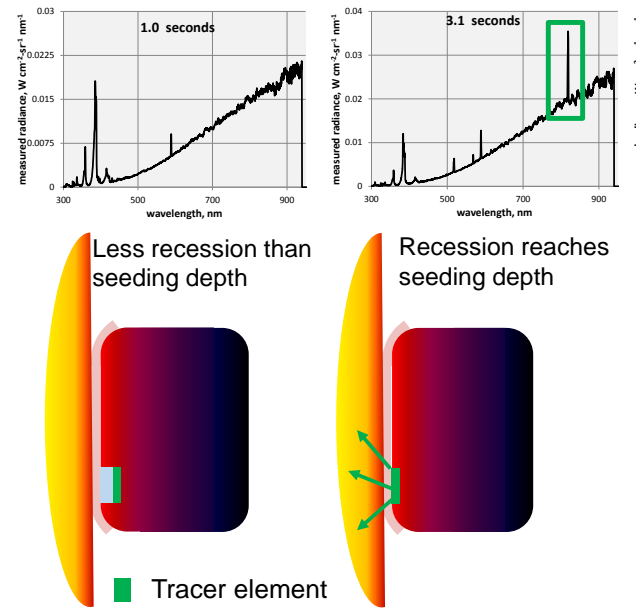

Recession reaches seeding depth
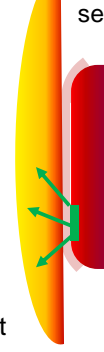

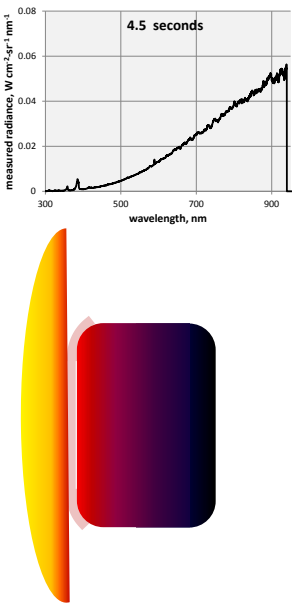

Figure 1. Illustration of remote recession sensing; spectra obtained during mArc testing. ${ }^{5}$

In preliminary experiments in a subscale developmental arcjet facility (mArc) at NASA Ames, the feasibility of this method was demonstrated by testing samples made of phenolic impregnated carbon ablator (PICA) which were 
seeded with rods made of a polymer matrix which contained $\mathrm{NaCl}$ and $\mathrm{MgCl}_{2} .{ }^{5}$ The heat flux to the sample was measured to about $1,000 \mathrm{~W} / \mathrm{cm}^{2}$. The emission lines of magnesium and sodium were shown to be clearly visible on top of the thermal emission of the glowing sample. They appeared in the emission spectra at about 1.5 seconds after insertion and disappeared 3 seconds later as shown in Fig 2. A recession rate calculated from this time and the dimensions of the seed material was in good agreement with the value determined post-test from the total recession of the sample.

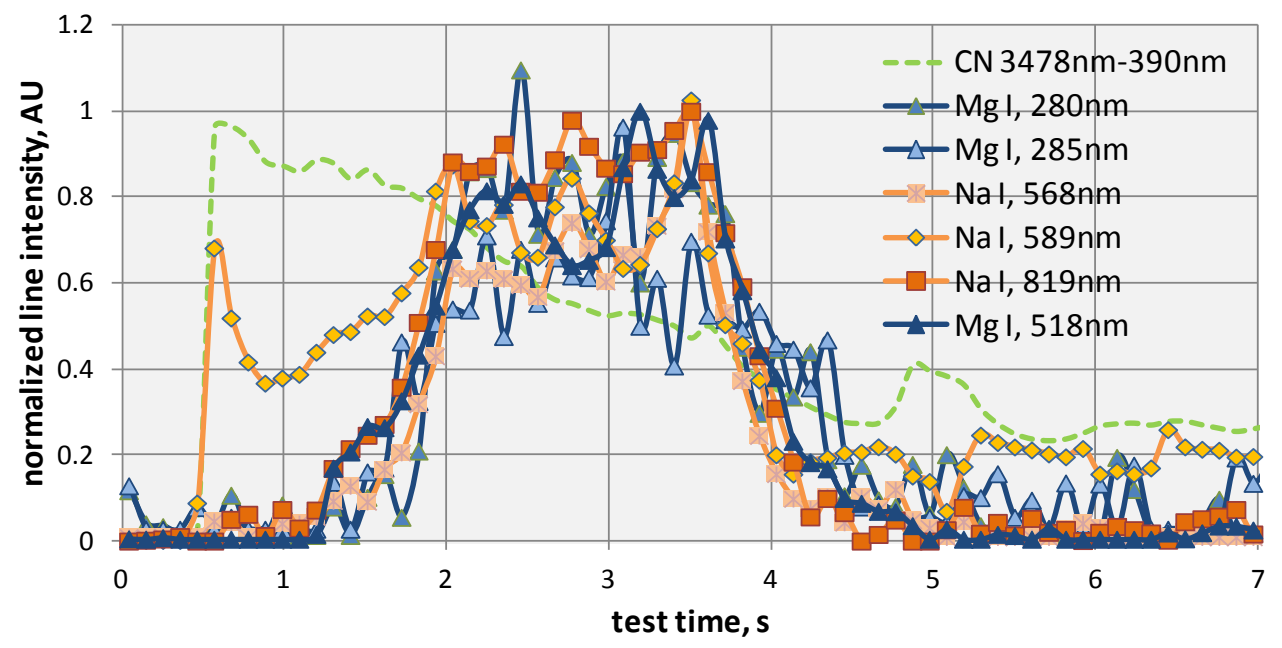

Figure 2. Time trace of normalized spectrally integrated line emission of sodium and magnesium during mArc testing vs. sample insertion time. ${ }^{5}$

While this previous experiment showed proof of concept of the technique, additional refinement is still needed. The method needs optimization such as signal intensity enhancement. Furthermore, more species need to be tested in order to allow measurements at multiple depths to be made remotely. This is the motivation for the current work. A method of delivery of the seed material to PICA samples was developed at NASA Ames, seed materials were selected, and three in-depth seeded samples were tested in the HYMETS facility 7,8 at NASA Langley. In the following, the strategy for delivering the seed materials into the PICA samples, the set-up used during HYMETS testing, and the results from these tests are described.

\section{Seeding Methodology}

Consideration has to be given to the selection of appropriate seed materials for remote recession sensing purposes. The physical properties of the chosen seed need to be suitable in the range of surface temperatures achieved during recession testing. If a materials melting or boiling temperature is too low it would likely evaporate and entrain with or interact with the pyrolysis gas generated by the phenolic material rather than indicate the recession process. The seed material must also be stable and non-reactive with either water or the PICA precursor solution. For an external observation during reentry, the spectral response characteristics of the seed material need to provide radiation which is visible on top of the thermal continuum emitted by the glowing surface at wavelengths above the absorption threshold of the atmosphere. The ideal particle size would be on the micron scale as a large surface area to volume ratio would help the phase transfer and spectral emission of the seed material in the post shock region. The materials used in this study represent suitable options that satisfy these requirements.

\section{A. Delivery Methods}

For a remote recession measurement method to provide useful information about the rate of recession, the location of the seed material relative to the receding surface and the extent of seed material need to be known as accurately as possible. Several methods of seed material delivery and placement were tested using FiberForm, the carbon fiber substrate of PICA. Delivery of the seed material with a solvent or epoxy as administered with a hypodermic needle proved to provide little control in how much of the FiberForm received the seed material.

A small amount of solvent or epoxy would wick through the porous material leaving no control on the size of the seeded region as seen in Figure 3. This result inspired the idea of infusing FiberForm with a seeded epoxy and machining it so a seed disk insert that could be placed at a defined location and depth in a TPS material. An extension of this method would be the creation of a seeded PICA material by incorporating the seed materials into the PICA manufacturing process. 


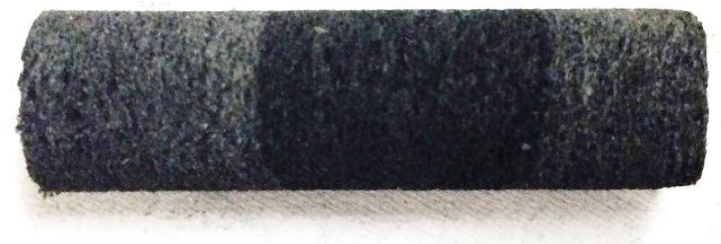

Figure 3. FiberForm material where a seed material has been delivered with an epoxy resin which wicks through the material creating the darkened seeded region of uncontrollable size and quality.

The candidate materials must be tested to verify their compatibility with for the PICA infusion process. A selection criterion is the capability of seed particle to remain suspended in the PICA precursor material. Two tests were performed to characterize how well the seed particles would remain in suspension, the first being conducted in isopropanol. Samples were prepared by thoroughly mixing a nominal $0.5 \mathrm{~g}$ of seed material in a $20 \mathrm{ml}$ vial of isopropanol. The samples were allowed to settle for three hours and afterwards the isopropanol with material in suspension was pulled off into a separate vial leaving the precipitate in the original vial. The isopropanol suspension was then placed under vacuum to aid evaporation, leaving just the material that had been in suspension. $\mathrm{Al}_{2} \mathrm{O}_{3}$ and $\mathrm{HfO}_{2}$ performed the best out of the selected materials with more than $10 \%$ remaining in suspension compared to less than $2 \%$ in suspension as shown in Table 1.

Table 1. Percentage of candidate seed material which remains suspended in isopropanol after three hours of settling time.

\begin{tabular}{cc}
\hline \hline Material & Suspension, \% \\
\hline $\mathrm{Al}_{2} \mathrm{O}_{3}$ & 56.46 \\
$\mathrm{HfO}_{2}$ & 12.83 \\
$\mathrm{VB}_{2}$ & 1.33 \\
$\mathrm{Al}$ & 1.06 \\
$\mathrm{SiC}$ & 0.81 \\
$\mathrm{TiO}_{2}$ & 0.80 \\
$\mathrm{ZrO}_{2}$ & 0.61 \\
$\mathrm{TaN}$ & 0.56 \\
\hline \hline
\end{tabular}

The top four seed materials for suspension in isopropanol, with the addition of silicon, were selected to be tested for suspension in the PICA precursor solution which is the material that is infused into the FiberForm in the making of PICA. The sample preparation followed that of the isopropanol tests with the exception of nominally $1 \mathrm{~g}$ of seed material being used. An additional test was conducted using magnesium chloride as the seed particle but the precursor solution reacted with ths seed material resulting in an unsuitable candidate.

To determine the amount of seed materials that remained in suspension, multiple density measurements of the seeded precursor were performed. The normalized results are shown in Figure 4.A slurry density formula was used to calculate the percentage of seed material remaining in suspension (compare Table 2). The suspension of candidate seed materials did not behave similarly between the precursor and isopropanol. An increase in suspension of Aluminum and $\mathrm{VB}_{2}$ was seen with the precursor compared to isopropanol, while a decrease in suspension was seen with $\mathrm{Al}_{2} \mathrm{O}_{3}$ and $\mathrm{HfO}_{2}$. Silicon was chosen to study how well it infuses throughout PICA with varying seed loads, since it had the largest particle size (44 micron) of the prior group.

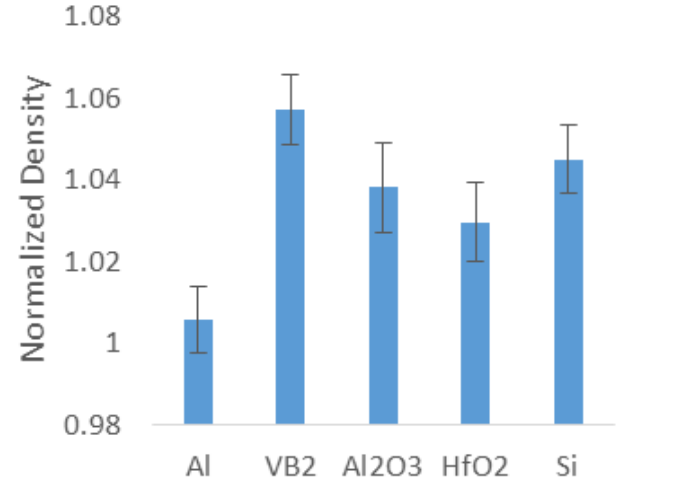

Figure 4. Normalized density of the PICA precursor solution with seed materials. 
Table 2. Percentage of candidate seed material remaining suspended in the PICA precursor solution after three hours of settling.

\begin{tabular}{cc}
\hline \hline Material & Suspension, \% \\
\hline $\mathrm{Al}$ & 1.41 \\
$\mathrm{Al}_{2} \mathrm{O}_{3}$ & 4.03 \\
$\mathrm{HfO}_{2}$ & 3.11 \\
$\mathrm{Si}$ & 4.72 \\
$\mathrm{VB}_{2}$ & 5.41 \\
\hline \hline
\end{tabular}

\section{B. SEM Elemental Analysis of Seeded PICA}

Four PICA samples were created following the standard PICA fabrication procedure except adding a high, medium, low, or no amount of silicon as a seed material to the precursor solution to determine the minimum loading required for a given volume. The low seed sample suffered damage to the edges of the sample during extraction rendering a density measurement and edge sampling impractical. The samples were weighed and then cleaved in two parts. The cleaved samples were analyzed using an energy dispersive X-ray spectroscopy (EDAX) to show the concentration and distribution of the Silicon seed material. The standard result for this type of analysis is an energy distribution, demonstrated for the high loading case and for the control case in Fig. 5. For the high loading case, there is a peak at the energy level corresponding to Silicon which is not present for the control case; indicating the silicon seed material was able to infuse throughout the PICA material.

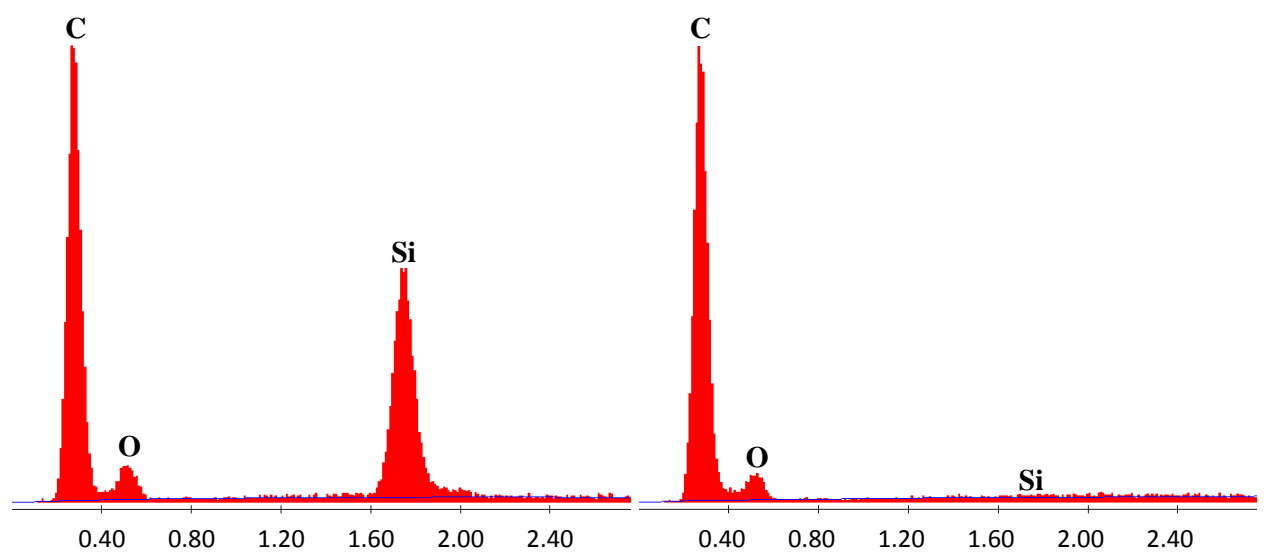

Figure 5. Left) EDAX response for the high loading of Silicon showing peaks corresponding to carbon, oxygen, and silicon. Right) EDAX response for the control sample showing a response only for carbon and oxygen.

Table 3. Details of the three Si load cases and the control PICA sample.

\begin{tabular}{ccccc}
\hline \hline Loading & Mass of Si, g & $\begin{array}{c}\text { Final Density, } \\
\text { g/cc }\end{array}$ & $\begin{array}{c}\text { Edge Si } \\
\text { Concentration, \% }\end{array}$ & $\begin{array}{c}\text { Center Si } \\
\text { Concentration, \% }\end{array}$ \\
\hline High & 2.001 & 0.299 & 5.55 & 2.85 \\
Medium & 0.204 & 0.283 & 1.63 & 0.51 \\
Low & 0.034 & - & - & 0.09 \\
Control & 0.000 & 0.280 & 0.05 & 0.07 \\
\hline \hline
\end{tabular}

Elemental mapping and statistics were performed at the edge of the sample and then at the center to understand how effectively the seed particle is able to infuse through the FiberForm material along with the precursor solution as a carrier. The elemental mapping for the high silicon loading case is presented in Fig. 6 where the blue regions are the response from silicon. The concentration of seed was the highest at the edge of the PICA sample and decreased towards the center region showing that a gradient occurs, likely induced by the seed particle size. The small levels, 
less than $0.10 \%$, of silicon detected in the low loading and control samples are within the measurement uncertainty baseline of the machine and would indicate very minimal to no silicon seed in those two cases.
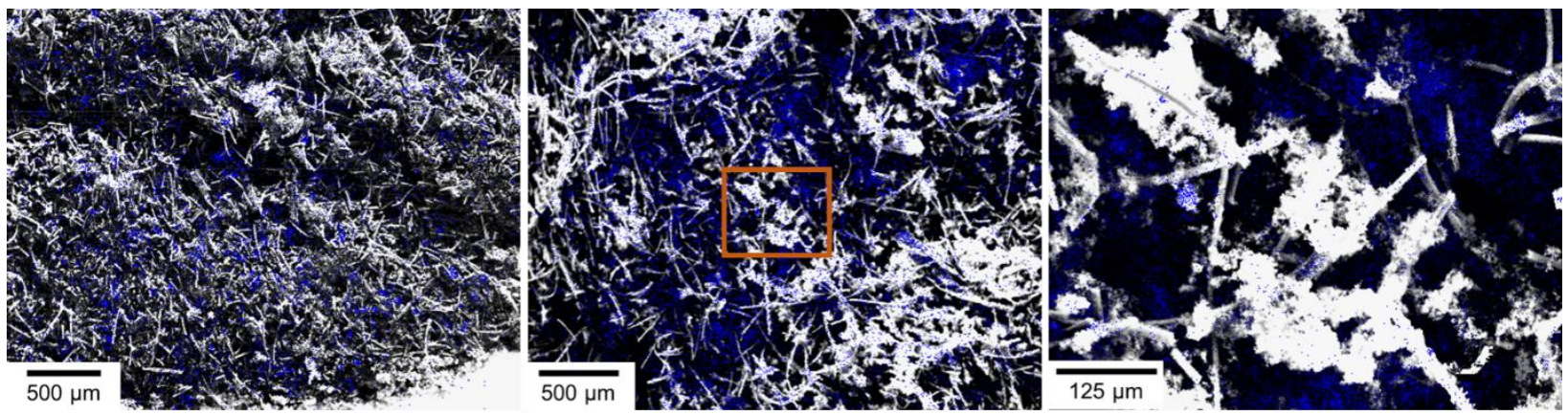

Figure 6. Elemental mapping of the high loading case showing the distribution of silicon at the a) edge, b) center, and c) center zoomed in area of $b$ as denoted by the orange rectangle.

\section{Test Sample Preparation}

Two versions of seed infused PICA were produced to be used in arcjet test samples and for further characterization as listed in Table 4. Samples A and B were prepared by machining a core from the backside of a PICA sample and replacing it with a seeded PICA insert. This allows for recession to occur through about $1.7 \mathrm{~mm}$ of normal PICA before the seeded PICA is reached and will proceed to recess through a seeded section of PICA for the remaining duration of the test. A third test sample, designed to replicate the mArc tests, was created using an epoxy encapsulated seed disk of magnesium chloride and sodium chloride that was inserted into a segment of PICA machined from the back side and backed with a nominal PICA plug. Each of the samples was then inserted into a collar and affixed with RTV, as viewed in assembled state in Fig. 7. The RTV, comprised of silicon and iron oxide, is the red material seen on the surface of the sample between the collar and the PICA. A Li-2200 collar was used for protection from side heating but also forces the pyrolysis gasses to leave through the front of the sample. Li-220 is primarily composed consists primarily of $\mathrm{SiO}_{2}$.
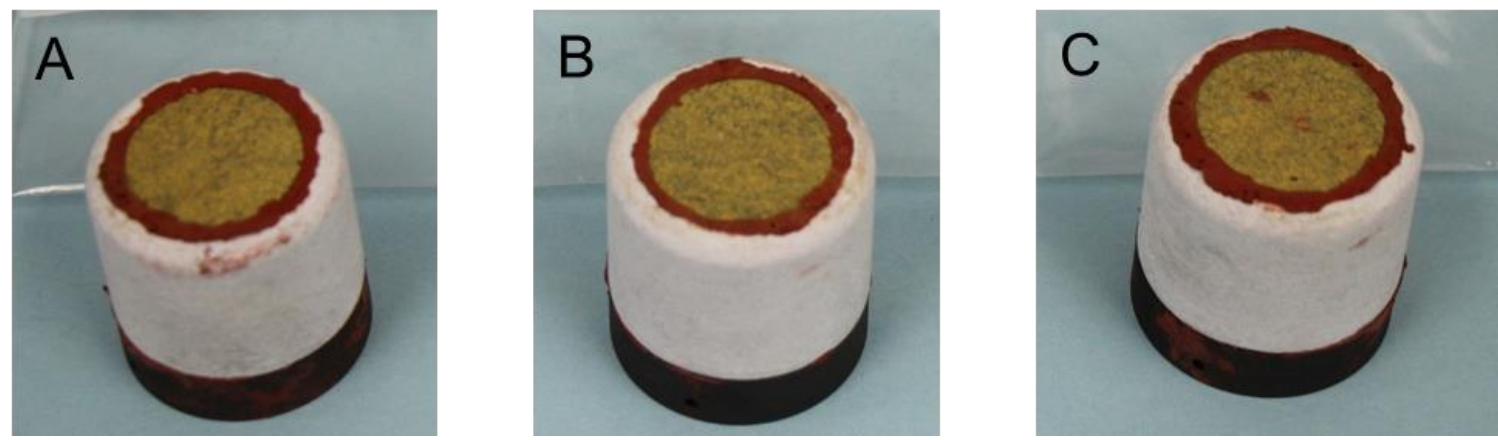

Figure 7. Final assembly of the three seeded PICA test samples. The red ring is RTV, the white collar encompasses the PICA sample and attaches it to the black graphite adapter for mounting in the HYMETS sample support system.

Table 4. Seed material type and amount for the seed infused PICA cores used in Samples A and B.

\begin{tabular}{cccc}
\hline \hline \multicolumn{2}{c}{ Sample A } & \multicolumn{2}{c}{ Sample B } \\
\hline \multicolumn{1}{c}{ Material } & Amount, g & \multicolumn{1}{c}{ Material } & Amount, g \\
\cline { 3 - 4 } $\mathrm{Al}$ & 1.523 & $\mathrm{Al2O}$ & 1.530 \\
$\mathrm{Si}$ & 1.599 & $\mathrm{SiO} 2$ & 1.267 \\
$\mathrm{HfO} 2$ & 1.517 & $\mathrm{HfC}$ & 1.561 \\
$\mathrm{VB} 2$ & 1.522 & $\mathrm{TiC}$ & 1.547 \\
\hline \hline
\end{tabular}




\section{Experimental Setups for HYMETS Testing}

The NASA Langley HYMETS arcjet is one of the NASA ground test facilities for the experimental investigation of thermal protection materials. A $400 \mathrm{~kW}$ power supply is used to run a segmented-constrictor direct-current electric arc heater, which serves as the arc plasma generator. Test gasses are injected tangentially into the bore to produce a vortex flow, which spin-stabilizes the electric arc of the plasma generator. The heated mixture is then accelerated through a convergent-divergent 8-degree half-angle Mach 5 conical nozzle with a 12.7 -mm diameter throat. To increase the footprint of the arc and thus protect the electrodes from rapid oxidation, argon (Ar) is injected near the anode. After passing through the test section, the flow exhausts into a $0.6-\mathrm{m}$ diameter by $0.9-\mathrm{m}$ long vacuum test chamber. A high capacity pumping system is used to evacuate the stagnated flow from the facility after being cooled. Depending on the tunnel conditions, the facility can be operated by a single technician, continuously, and for several hours. ${ }^{7,8}$

For the emission spectroscopy measurements, an Andor Shamrock spectrometer with $500 \mathrm{~mm}$ focal length in combination with a Princeton Instruments PIXIS:400BR_eXcelon CCD was used for spectral dispersion and detection. The spectrometer observed the stagnation region in front of the PICA samples through a side window of the HYMETS facility. The 150 lines/mm grating allowed for a simultaneous detection of a wavelength range from $204 \mathrm{~nm}$ to $550 \mathrm{~nm}$ with a spectral resolution of $\sim 0.26 \mathrm{~nm}$. A $445 \mathrm{~mm}$ focal length parabolic mirror and several redirecting mirrors were used to image a horizontal line onto the vertical entrance slit of the spectrometer. Since the sample position was not directly accessible through the side window, an additional periscope consisting of two mirrors under $45^{\circ}$ tilt was placed inside the vacuum chamber to give a perpendicular line of sight onto the flow axis. In addition, a separate optical system, shown on the top right of Fig. 8, used a Thorlabs mirror collimator pointed at the sample front surface. This collimator imaged approximately the whole front surface of the sample. The signals were fed through an optical fiber to a Stellarnet Black Comet miniaturized spectrometer with a spectral range from $200 \mathrm{~nm}$ to $1,100 \mathrm{~nm}$ and a pixel resolution of $0.5 \mathrm{~nm}$ and time resolved spectra were taken over the insertion time of the sample. Figure 8 illustrates the emission spectroscopy setups and the viewing geometry inside the HYMETS chamber.

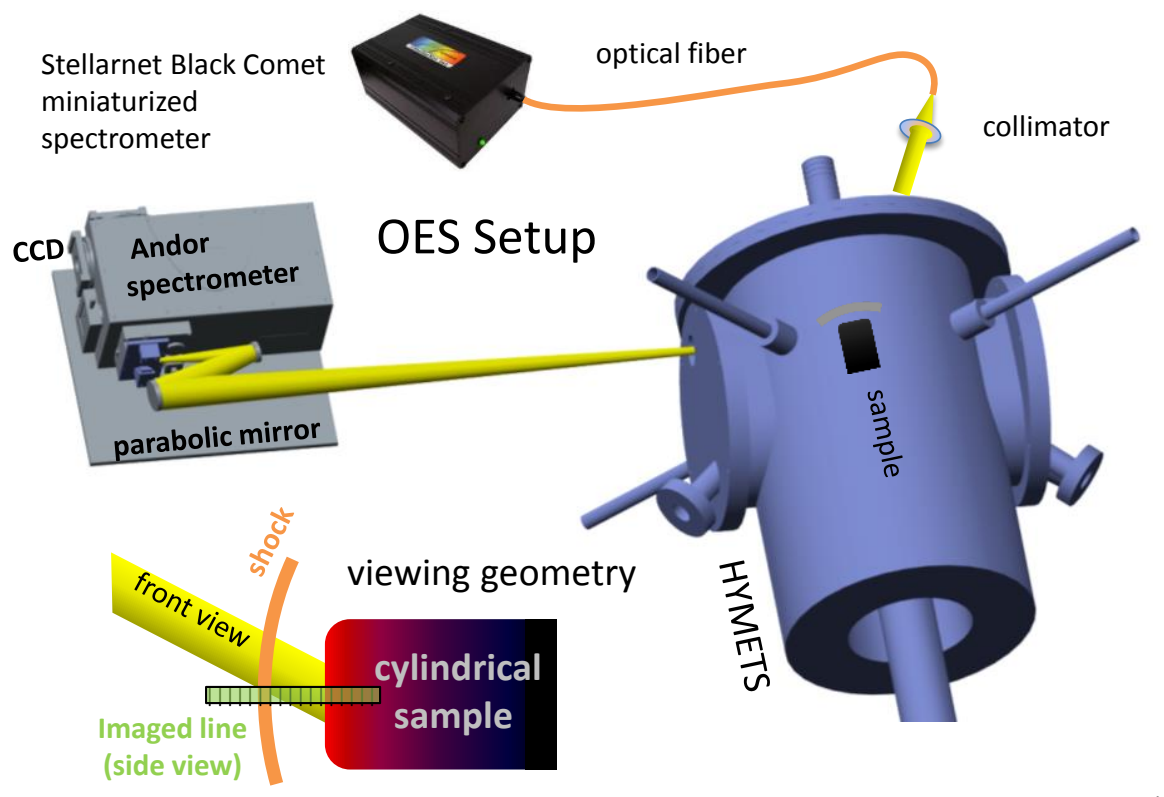

Figure 8. Setup for optical emission spectroscopy (OES) from the side with an Andor imaging spectrometer and from the front with a miniaturized fiber couples spectrometer and viewing geometry inside the HYMETS.

The CCD array height of $8 \mathrm{~mm}$ allowed for monitoring a line of $22 \mathrm{~mm}$ length inside the HYMETS facility. Focusing was done by imaging LEDs of different color on the camera with the grating tuned to zero order therefore producing an image without spectral resolution. Intensity calibration of both spectrometers was done through measuring the emission of a miniaturized spectral radiance source (Gigahertz-Optik BN-0102) calibrated between $300 \mathrm{~nm}$ and 1,100 nm and a deuterium lamp (Bentham CL3) calibrated to spectral irradiance between $200 \mathrm{~nm}$ and $400 \mathrm{~nm}$. The irradiance values from the Deuterium lamp were used to obtain the spectral sensitivity in the UV and were scaled to the radiance values obtained from the Gigahertz lamp in the overlapping spectral region to achieve a calibration to spectral radiance over the entire measured spectrum. 


\section{Experimental Data and Analysis}

Three seeded samples were available for testing (A, B, and C). The method of delivery varied as described above, the seeding depth from the sample surface was roughly the same for all samples. Table 5 summarizes the sample configuration. All samples were tested at a condition with 300 SLM air as working gas, a stagnation pressure of $44 \mathrm{mbar}$, and a nominal cold wall heat flux of $200 \mathrm{~W} / \mathrm{cm}^{2}$ yielding sample surface temperatures between 3,800 and $3,900^{\circ} \mathrm{F}(2,366$ and $2,422 \mathrm{~K})$. For PICA samples without a collar, recession rates of about $0.1 \mathrm{~mm} / \mathrm{s}$ were seen in earlier tests at that condition.

Table 5. Seeding information for the tested samples.

\begin{tabular}{clll}
\hline \hline Sample & Seeding method & Seed elements & Seeding Depth \\
\hline $\mathrm{A}$ & infused into a core of PICA & $\mathrm{Al}, \mathrm{Si}, \mathrm{HfO}_{2}, \mathrm{VB}_{2}$ & $1.76 \mathrm{~mm}$ \\
$\mathrm{~B}$ & infused into a core of PICA & $\mathrm{Al}_{2} \mathrm{O}_{3}, \mathrm{SiO}_{2}, \mathrm{TiC}, \mathrm{HfC}$ & $1.65 \mathrm{~mm}$ \\
$\mathrm{C}$ & encapsulated in an epoxy disk & $\mathrm{NaCl}_{\mathrm{MgCl}}$ & $1.69 \mathrm{~mm}$ \\
\hline \hline
\end{tabular}

The high-resolution emission spectroscopy data from the side view was taken with an entrance slit width of $30 \mu \mathrm{m}$, and an acquisition time of $120 \mathrm{~ms}$ yielding a frame rate of 2.5 frames per second. In each frame the post shock region from shock to the sample surface (which is about $3 \mathrm{~mm}$ thick) is resolved with about 50 spectra showing spatial distribution of the observed radiation in this region. However, for the analysis of the seed elements, the temporal change contains the important information, i.e. when individual species show up in the measured spectra. Therefore, the spatial information in all spectra in each frame were summed up after being individually calibrated which corresponds to running the camera in full vertical binning mode, showing the total spectral emission of the entire post shock layer. The resulting spectra were plotted over time after sample insertion as shown in Fig. 9 for sample A, seeded with $\mathrm{Al}, \mathrm{Si}, \mathrm{HfO}_{2}$, and $\mathrm{VB}_{2}$, infused into a core of PICA.

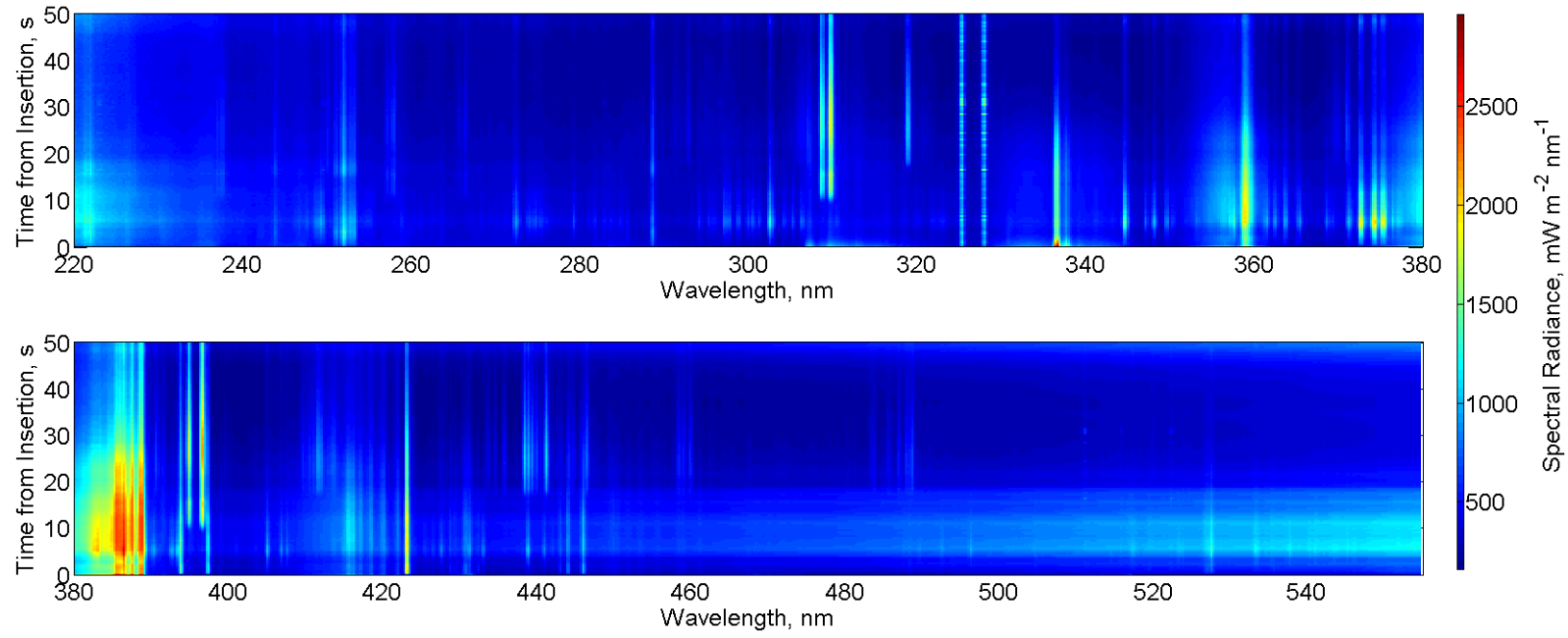

Figure 9. Time trace of integrated emission over the entire post-shock layer in front of sample A, seeded with $\mathrm{Al}, \mathrm{Si}, \mathrm{HfO}_{2}$, and $\mathrm{VB}_{2}$, infused into a core of PICA. Top: $220 \mathrm{~nm}$ to $380 \mathrm{~nm}$, bottom: $380 \mathrm{~nm}$ to $555 \mathrm{~nm}$.

The spectrum shown in the bottom-most row of Fig. 9 was taken right after sample insertion. The spectra evolve with test time towards the top of the figure. For the sake of clarity, the total wavelength range is split up in two regions from $220 \mathrm{~nm}$ to $380 \mathrm{~nm}$ (upper picture in Fig. 9) and from $380 \mathrm{~nm}$ to $555 \mathrm{~nm}$ (lower picture). The strong emission lines at 325 and $328 \mathrm{~nm}$ are from copper due to electrode erosion in the arcjet and are present in all spectra. Nearly all emission between $340 \mathrm{~nm}$ and $388 \mathrm{~nm}$ is likely to be from CN radiation, while the molecular bands near $336 \mathrm{~nm}$ are due to $\mathrm{NH}$. Both can originate from plasma interactions with the silicon bond material RTV on the sample surface, with the collar material, and with pyrolysis products from PICA itself. The strong emission lines at 393, 397, and $423 \mathrm{~nm}$ are due to $\mathrm{Ca}$ and $\mathrm{Ca}^{+}$which is found in the carbon FiberForm itself. ${ }^{9}$ Emission characteristic for the seed elements is seen from aluminum (Al) and vanadium (V). Strong Al lines are seen at 308, 310, 395, and $396 \mathrm{~nm}$ and appear at about $10 \mathrm{~s}$ after sample insertion. The strongest $\mathrm{V}$ lines are seen at 318 and $441 \mathrm{~nm}$ and appear after about 17 seconds, despite the fact that they were both seeded at the same location in the sample. Neither hafnium nor boron were identified in the spectra. 
For the following analysis, the line integrals were built by summing all intensities of the corresponding line and subtracting an underlying trapezoid due to background emission (particularly important in wavelength regions with strong thermal continuum radiation). If normalized to their respective maxima, the time history of all aluminum lines followed the same profile, as did the individual vanadium lines. Representative for the other lines, the time history of the line intensities normalized to their respective maximum of $\mathrm{Al}$ at $310 \mathrm{~nm}$ and $\mathrm{V}$ at $318 \mathrm{~nm}$ are shown in Fig. 10. As an example for emission from samples without seed material, NH is added which starts emitting right after sample insertion.

The $\mathrm{Al}$ emission starts at about $10 \mathrm{~s}$, has a peak at about $15 \mathrm{~s}$, a local minimum at $19 \mathrm{~s}$ and a second peak after $30 \mathrm{~s}$. The vanadium emission starts at about $17 \mathrm{~s}$ and follows qualitatively the time profile of the $\mathrm{Al}$ emission. If compared to images of the front surface of the sample during the test as shown in Fig 11, the seeded rod becomes visible on the front surface at about $17 \mathrm{~s}$ after insertion which agrees very well with the time the vanadium lines start being visible in the emission spectrum. Therefore the vanadium emission is interpreted as a suitable indicator for recession reaching the seeding depth. At 10 seconds when the aluminum emission starts to significantly increase, the recession has not yet reached

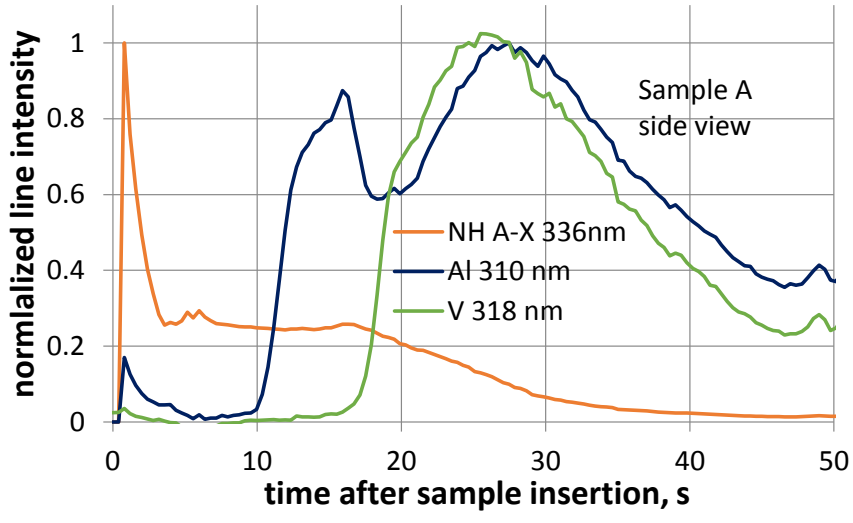

Figure 10. Line intensities of $\mathrm{Al}(310 \mathrm{~nm}), \mathrm{V}(318 \mathrm{~nm})$, and $\mathrm{NH}$ $(336 \mathrm{~nm})$ integrated over the entire post-shock layer in front of sample A vs. test time after sample insertion. the seeded part.

Although the collar material does contain some aluminum, the absence of $\mathrm{Al}$ lines in the spectra collected right after the injection, confirms than no contribution to the observed emission is due the collar.. Therefore, the Al emission is believed to be $\mathrm{c}$ ascribed to $\mathrm{Al}$ seeds transported by pyrolysis gases and blown into the boundary layer before recession reaches the seeding depth. As hypothesized, the radiation from the materials with lower melting and evaporation temperature indicates interactions with the pyrolysis gases rather than being an indicator for recession. Unfortunately, the seeded samples were not instrumented with in-depth thermocouples, otherwise the appearance of aluminum in the emission spectra could be linked to a temperature of the sample at the seeding depth at that time.
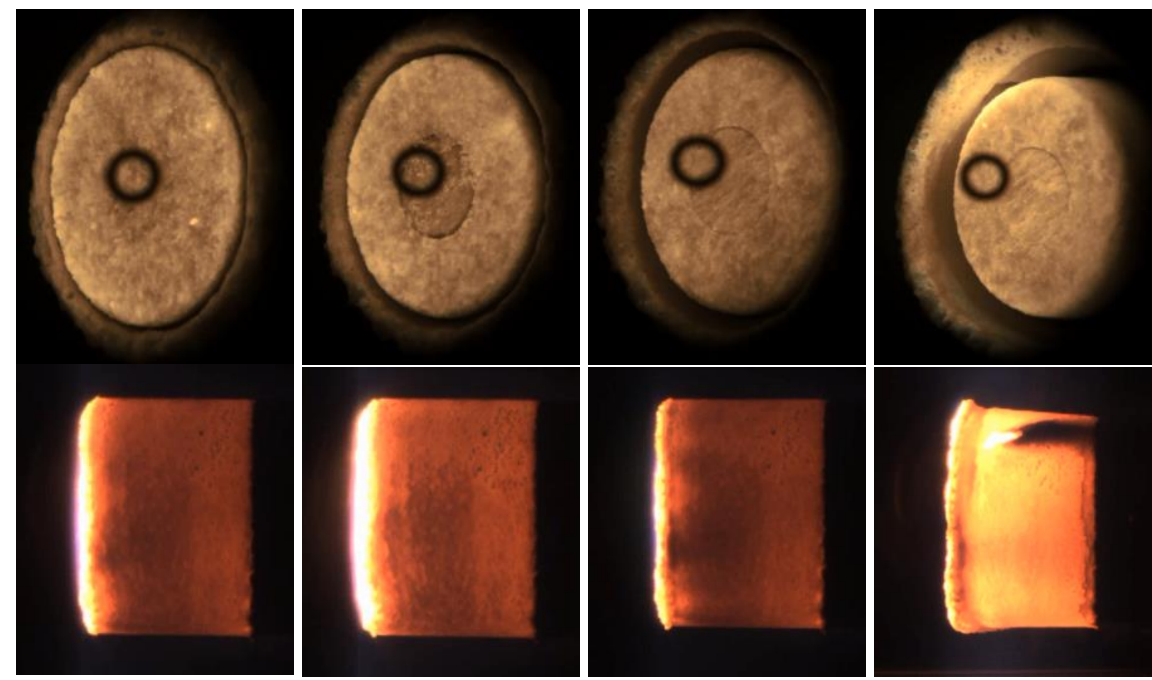

Figure 11. Front (top row) and side (bottom row) view of sample $A$ at 10, 17, 30, and 59 seconds after sample insertion. (The black ring in the front view is a marker for the pyrometer measurement and no physical feature of the sample itself.)

The same procedure of calculating line intensities was performed for the front view spectra measured with the fiber-coupled miniaturized spectrometer. Due to the lower spectral resolution, and due to the large area of glowing 
sample covered, the emission lines do not stand out as clearly as in the side view. However, line intensities could be extracted for aluminum and vanadium and show the same trends as seen in the side view, as illustrated in Fig. 12.
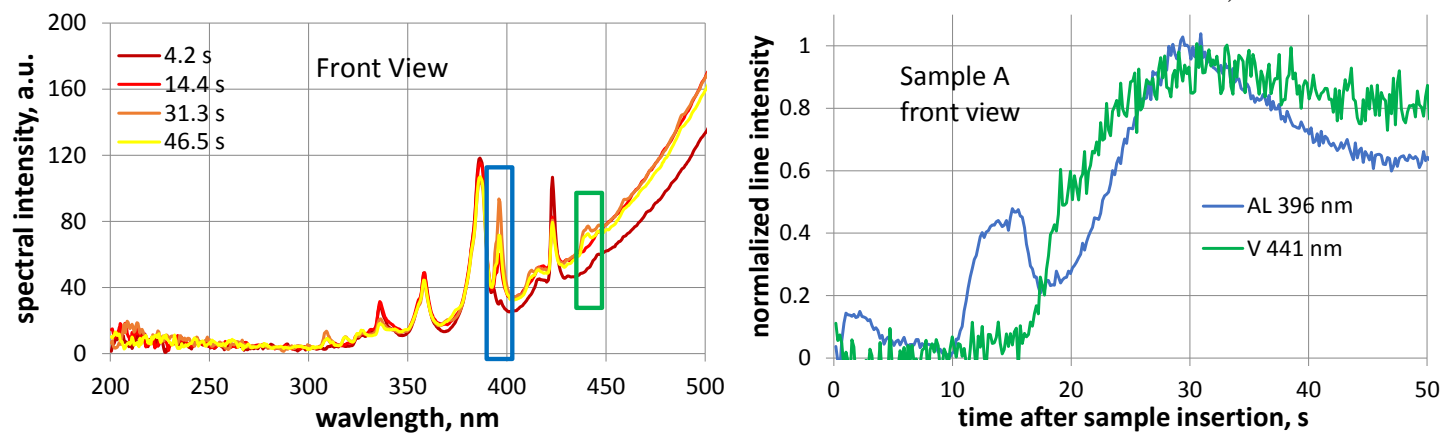

Figure 12. Front view spectra of sample $A$ at increasing times after sample insertion (left) and line intensities for aluminum (emission line at $395 \mathrm{~nm}$ ) and vanadium (emission line at $441 \mathrm{~nm}$ ) (right).

Figure 13 shows FVB spectra for sample $\mathrm{B}$, seeded with $\mathrm{Al}_{2} \mathrm{O}_{3}, \mathrm{SiO}_{2}, \mathrm{TiC}$, and $\mathrm{HfC}$, infused into a core of PICA. As for Sample A, strong emission of copper, CN, calcium and NH is seen. The emission of seeded silicon cannot be separated from the silicon coming from the collar and is therefore not useful for recession measurements. The same is valid for carbon which is part of PICA itself. Again, hafnium could not be identified in the spectra.

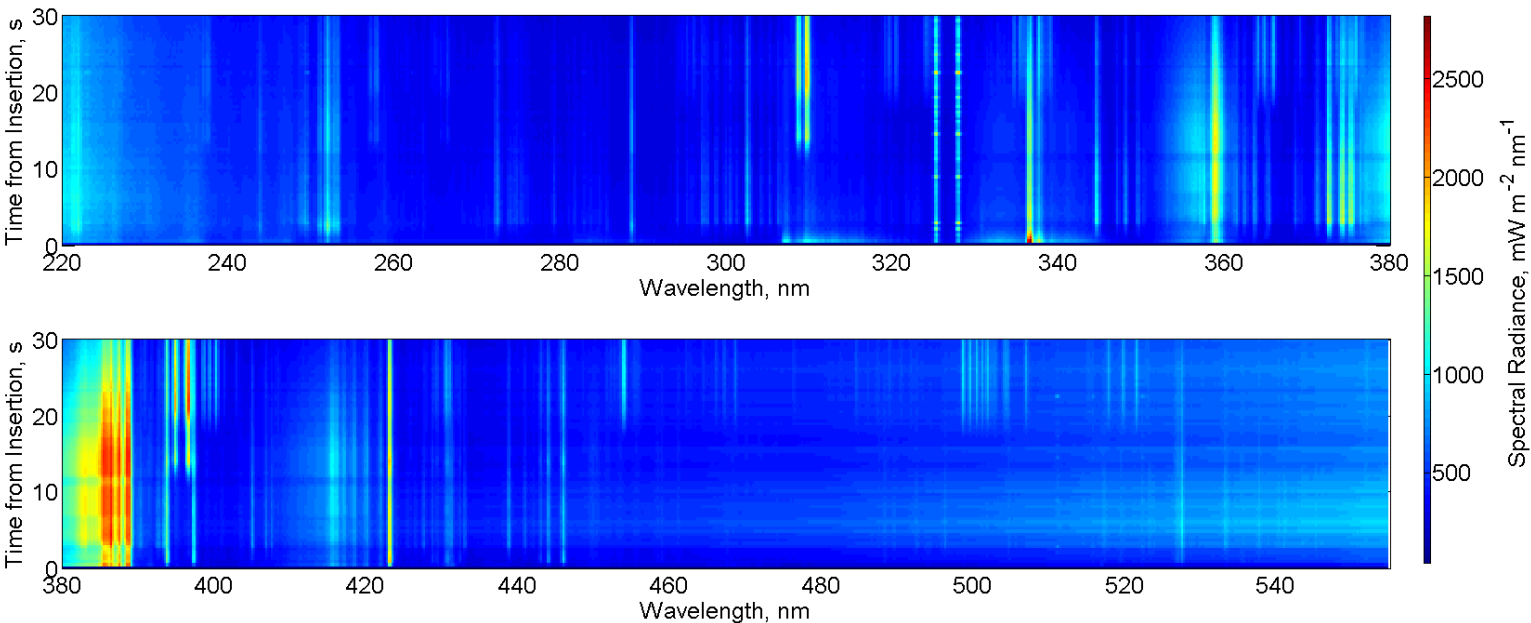

Figure 13. Time trace of integrated emission over the entire post-shock layer in front of sample $B$, seeded with $\mathrm{Al}_{2} \mathrm{O}_{3}, \mathrm{SiO}_{2}, \mathrm{TiC}$, and $\mathrm{HfC}$, infused into a core of PICA.

However, the emission of aluminum (308, 310, 395 , and $396 \mathrm{~nm}$ ) and titanium $(366,399$, and $453 \mathrm{~nm}$ and groups of lines around 500 and $519 \mathrm{~nm}$ ) can be clearly observed. As seen for sample A, the Al lines appear in the spectrum at about 10 seconds after sample insertion and show a local maximum at $14 \mathrm{~s}$. The titanium lines appear at about $17 \mathrm{~s}$ and peak at $25 \mathrm{~s}$. These times correlate very well with the aluminum and vanadium emission in the test of sample A. Consequently, it is concluded that the $\mathrm{Ti}$ emission indicates that recession reached the seeding depth. Examples for the time trace of line intensities (Al at 310 and $396 \mathrm{~nm}$, Ti at $453 \mathrm{~nm}$ and group around $500 \mathrm{~nm}$ ) are shown in Fig. 14 to illustrate this behavior.

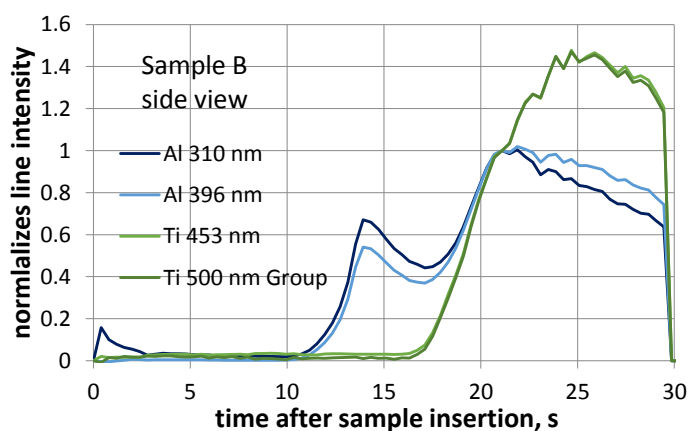

Figure 14. Line intensities of $\mathrm{Al}(310$ and $396 \mathrm{~nm})$ and $\mathrm{Ti}(453 \mathrm{~nm}$ and group around $500 \mathrm{~nm})$ normalized to their value at $21 \mathrm{~s}$ in front of sample B vs. test time after sample insertion.

The final sample (sample $\mathrm{C}$ ) was seeded with $\mathrm{NaCl}$ and $\mathrm{MgCl}_{2}$ encapsulated in an epoxy disk of $0.88 \mathrm{~mm}$ thickness which was very similar to the samples tested in the mArc facility except using a disk shaped epoxy seed 
rather than a rod. Fig. 13 shows FVB spectra for this sample in the side view with the Andor Shamrock spectrometer.

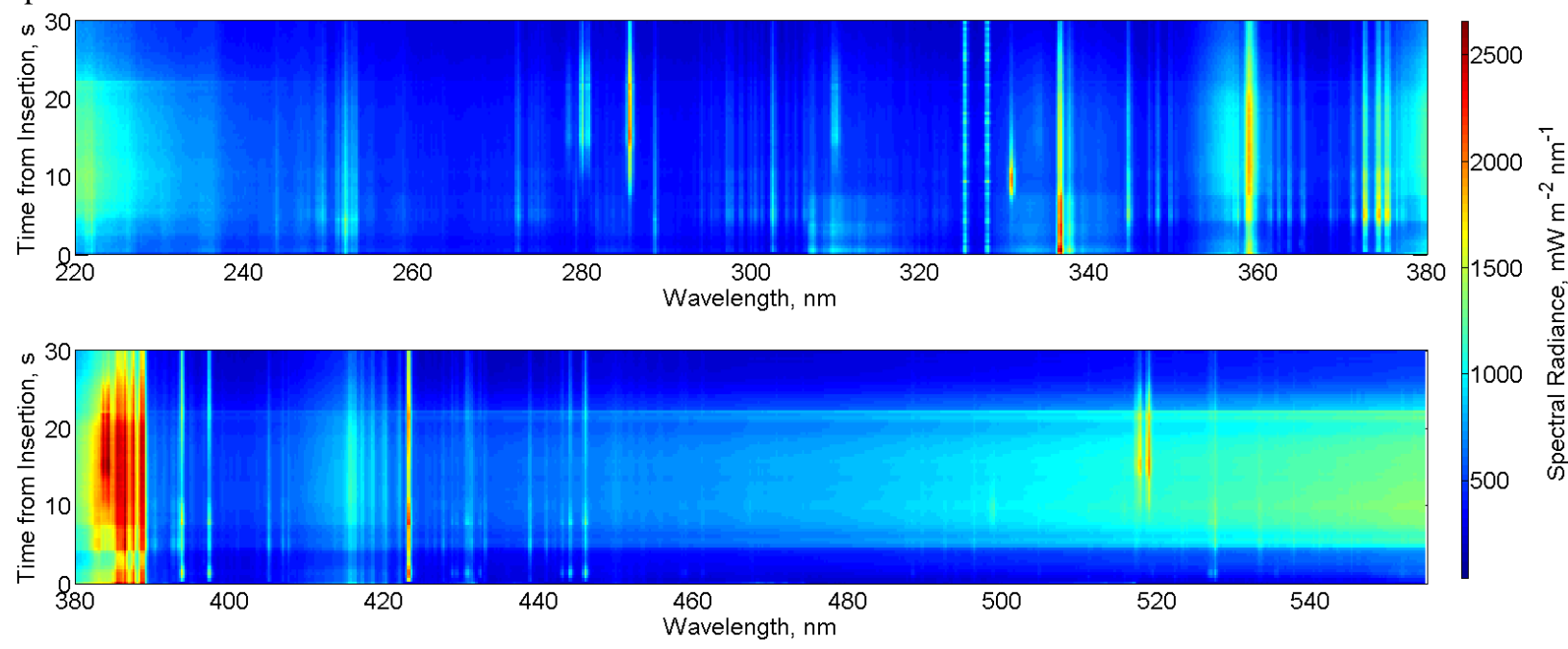

Figure 15. Time trace of integrated emission over the entire post-shock layer in front of sample $C$, seeded with $\mathrm{NaCl}$ and $\mathrm{MgCl}_{2}$ encapsulated in an epoxy disk of $0.88 \mathrm{~mm}$ thickness.

As in the previous samples, strong emission of copper, $\mathrm{CN}$, calcium and $\mathrm{NH}$ is seen. As in the mArc tests at NASA Ames, ${ }^{5}$ no signs of chlorine are found in the spectra. The emission of sodium with the strongest lines in this spectral range at 330 and $495 \mathrm{~nm}$ and magnesium with lines at 280, 384 (strongly overlapping with $\mathrm{CN}$ emission), 517 and $518 \mathrm{~nm}$ are clearly seen with distinct temporal profiles.

The Na lines start showing up at 7 seconds after sample insertion, have a maximum at $10 \mathrm{~s}$, and decay from there. The $\mathrm{Mg}$ lines start rising at about $7 \mathrm{~s}$, peak at $16 \mathrm{~s}$, but do not disappear entirely until the end of the test. Compared to samples A and B, the time the $\mathrm{Mg}$ lines appear in the spectrum agrees roughly with the time the $\mathrm{V}$ and $\mathrm{Ti}$ lines showed up, indicating that recession has reached the seeding depth. The $\mathrm{Na}$ lines, however, seem to leave the material with the pyrolysis gases. This disagrees with the results from earlier testing in the NASA Ames mArc facility where the $\mathrm{Na}$ and $\mathrm{Mg}$ lines showed the same time trace over test time. Furthermore, the emission of $\mathrm{Mg}$ (and to a lesser extend the one of $\mathrm{Na}$ ) does not vanish completely from the spectra.

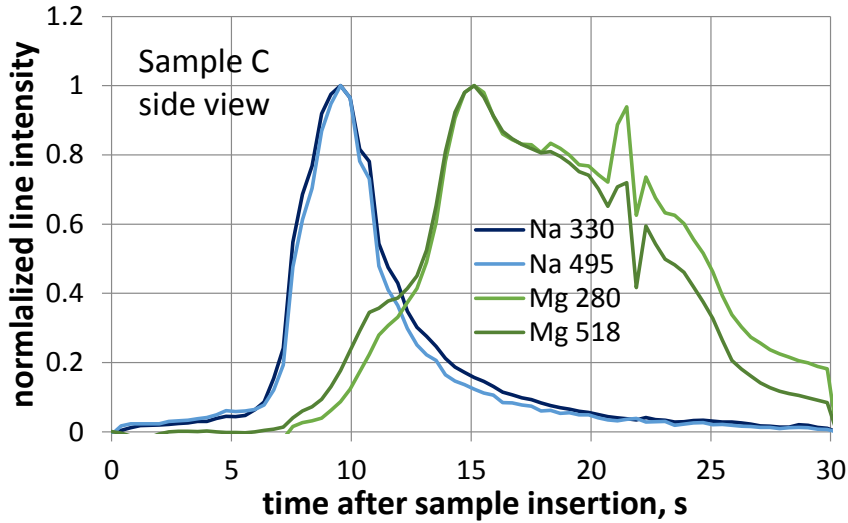

Figure 16. Line intensities of sodium ( 330 and $495 \mathrm{~nm})$ and magnesium ( 280 and $518 \mathrm{~nm}$ ) integrated over the entire postshock layer in front of sample $C$ vs. test time after sample insertion.

This might indicate some diffusion of seed material into the heat shield material. It is not entirely clear whether this might have happened during sample preparation or during the test itself. SEM investigations of the tested samples might give more information.

The line intensity time histories derived from the front view fiber-coupled miniaturized spectrometer as shown in Fig. 17 are in good agreement with the side view results. $\mathrm{Na}$ and $\mathrm{Mg}$ lines are clearly seen in the spectra although the lines at higher wavelengths are easier to distinguish than the UV lines.

However, recession appears to reach the seeded disk at about $20 \mathrm{~s}$ after insertion as seen in photos of the front surface of the sample shown in Fig. 18. After two more seconds, the seeded area is completely visible. During this time, sharp peaks in the $\mathrm{Mg}$ emission are visible in the line intensity time history indicating increased magnesium ablation once the seed material comes in contact with the plasma. In the photographs it appears, though, that most of the seed material has already disappeared and that a step is visible. Some of the magnesium has left the sample together with the pyrolysis gases as indicated by the $\mathrm{Mg}$ emission starting even before $10 \mathrm{~s}$ after sample insertion. 
One hypothesis is that the epoxy used as a carrier pyrolyzes well before the recession reaches the seeding depth and carries both sodium and magnesium with it.
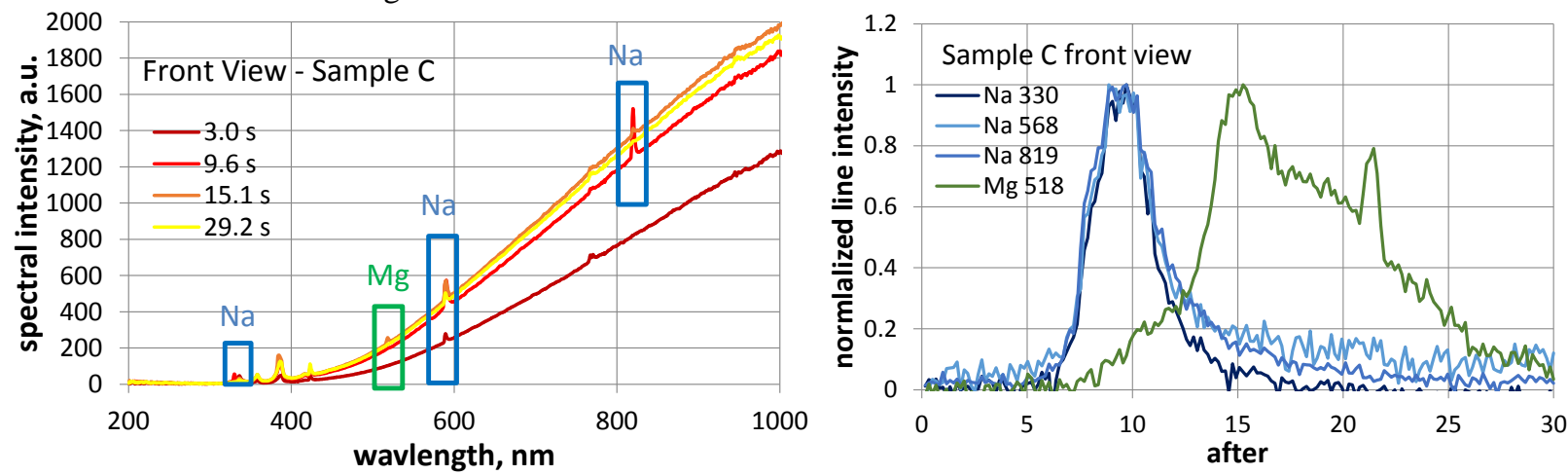

Figure 17. Front view spectra of sample $C$ at 3, 10, 15, and 29 seconds after sample insertion and line intensities for sodium $(330,568$, and $819 \mathrm{~nm})$ and magnesium $(518 \mathrm{~nm})$.
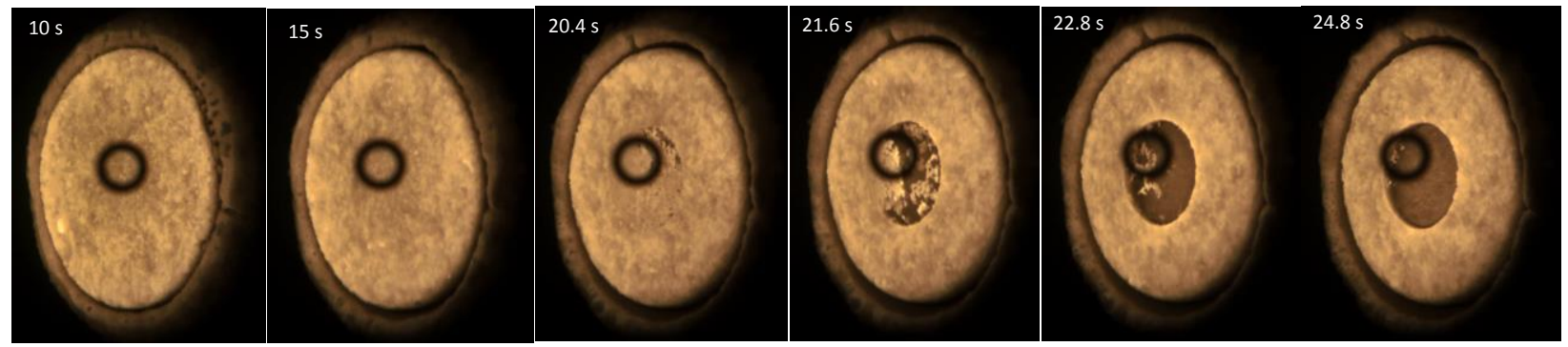

Figure 18. Front view of sample $C$ at different times after sample insertion.

With the exception of $\mathrm{Na}, \mathrm{Mg}, \mathrm{NaCl}$, and $\mathrm{MgCl}_{2}$, all seed products show boiling temperatures higher than the measured sample surface temperature (which is assumed to be the highest temperature over the whole sample volume). In general, materials with lower melting points than the surface temperature of the sample seem to show up in the post shock emission before recession has reached the seeding depth. It is interesting, though that the time history of Al emission for samples A and B is nearly identical although sample A was directly seeded with aluminum with a low melting temperature of $933 \mathrm{~K}$ which could be reached in the pyrolysis zone while sample B was seeded with $\mathrm{Al}_{2} \mathrm{O}_{3}$ with a melting temperature of $2345 \mathrm{~K}$ very close to the surface temperature. It might be useful to repeat such tests with $\mathrm{MgCl}_{2}$ and $\mathrm{MgO}$ which have drastically different melting temperatures but the same optical properties for the emitted radiation. Furthermore, the emission of titanium was clearly seen in the post-shock plasma although the seed material $\mathrm{TiC}$ has a higher melting temperature than the sample surface temperature. Table 6 illustrates the melting and boiling temperatures for the radiating elements and the original seed materials.

Table 6: Melting and boiling temperatures of seed materials and elements and approximate electronic excitation energies of transitions used in this work.

\begin{tabular}{lllclll}
\hline \hline Material & $\mathbf{T}_{\text {Melt }}, \mathbf{K}$ & $\mathbf{T}_{\text {Boiling, }}, \mathbf{K}$ & $\mathbf{E}_{\text {el exc, }} \mathbf{c m}^{-\mathbf{1}}$ & $\mathbf{M a t e r i a l}$ & $\mathbf{T}_{\text {Melting, }}, \mathbf{K}$ & $\mathbf{T}_{\text {Boiling, }} \mathbf{K}$ \\
\hline $\mathrm{Na}$ & 370 & 1155 & $\sim 17,000$ & $\mathrm{MgCl}_{2}$ & 987 & 1685 \\
$\mathrm{Mg}$ & 923 & 1364 & $\sim 35,000 ; \sim 41,000$ & $\mathrm{NaCl}$ & 1074 & 1686 \\
$\mathrm{Al}$ & 933 & 2792 & 25,$350 ; 34,435$ & $\mathrm{Al}_{2} \mathrm{O}_{3}$ & 2345 & 3250 \\
$\mathrm{Ti}$ & 1941 & 3560 & $20,000-25,000$ & $\mathrm{VB}_{2}$ & 2373 & \\
$\mathrm{~V}$ & 2183 & 3680 & $\sim 26,000 ; \sim 32,000$ & $\mathrm{MgO}$ & 3125 & 3873 \\
$\mathrm{Cu}$ & 1358 & 2835 & $\sim 31,000$ & $\mathrm{TiC}$ & 3433 & 5093 \\
\hline \hline
\end{tabular}




\section{Summary and Conclusions}

A method for remote recession measurements through emission spectroscopy measurements of the post shock layer radiation in front of a material sample in a plasma flow was studied experimentally. Different seed materials and different delivery methods were investigated. Processing investigations allowed the down-selection of $\mathrm{Al}_{2} \mathrm{O}_{3}$, $\mathrm{HfO}_{2}, \mathrm{VB}_{2}$ and $\mathrm{Al}$ as suitable candidates for seeding PICA samples. Two of those methods - infusing seed materials into a core of PICA and encapsulating seed material in an epoxy disk - were selected to produce material samples which were tested in the NASA Langley HYMETS arcjet facility at heating levels of $200 \mathrm{~W} / \mathrm{cm}^{2}$. The emission of the post shock layer was observed with a high resolution imaging spectrometer viewing the whole stagnation line from the side and with a fiber-coupled miniaturized spectrometer observing the sample surface in the wavelength range from $200 \mathrm{~nm}$ to $1,100 \mathrm{~nm}$ from the front through a collimator. The samples were encapsulated in $\mathrm{SiO}_{2}$ collar which was intended toprevent side wall heating but also forced the pyrolysis gases to leave through the sample front surface. Unfortunately, the collar material showed less recession than the PICA sample material therefore forming a rim which shaded the boundary layer close to the sample surface from observation through the side view spectrometer. Nevertheless, most of the seeded products were detected in the measured spectra. Seed elements with lower melting temperatures such as $\mathrm{Na}, \mathrm{Mg}$, and $\mathrm{Al}$ were seen in the post-shock emission spectra before the recession reached the actual seeding depth. One hypothesis is that they are carried with the pyrolysis gases and therefore not a clear sign for recession but for interactions with the pyrolysis gas at the seeding depth. This information could be useful in some applications, since it indicates the start of pyrolysis of the heat shield at that material depth. From photographs during the test it seems like the epoxy disk might have at least partly vanished before recession reached the seeding depth. The samples used here were not instrumented but if in-depth thermocouples would be used in future tests, it might be possible to assign defined pyrolysis zone temperatures to the emission of such seed materials. Seed materials with higher melting temperature such as V and Ti correlated nicely with the actual recession observed through a camera facing the sample front surface during insertion. Using $\mathrm{NaCl}$ and $\mathrm{MgCl}_{2}$ as seed materials, a clear separation of the emission of $\mathrm{Na}$ and $\mathrm{Mg}$ was seen in time which was not observed during mArc testing of similar seed material. No explanation for this discrepancy has been found so far. It also remains to show whether materials which are border-line in terms of melting temperature compared to the sample surface temperature such as magnesium can be used as an indicator of recession if delivered in the form of a material with high melting point such as magnesium oxide.

Future testing of additional seed materials would be desirable. Certainly, measured temperature distributions inside the test sample, e.g. through in-depth thermocouples would be helpful with the interpretation of seed material with low melting/evaporation temperatures. However, for economic reasons and due to limited availability, the large NASA arcjet facilities used for TPS qualification testing are not suitable for such parametric studies. To prepare this promising technology for application in real re-entry missions, a parametrical investigation in ground test facilities in an academic environment is a more cost-effective way to achieve a Technology Readiness Level which makes this technology eligible for future NASA missions. Therefore, it is planned to continue the investigation of remote recession in the form of parametric studies in low power plasma facilities at the University of Kentucky.

\section{Acknowledgments}

The work on remote recession measurements and development of facilities and methods for the investigation of gas-surface interactions is supported by NASA Kentucky under NASA awards No: NNX10AL96H and No: NNX13AB12A, and by NASA Ames through the research grant NNX15AN74A. Financial support for the experimental work at NASA Langley was provided by NASA Kentucky EPSCoR Award NNX10AV39A. The authors would like to thank Michael Wright and Nagi Mansour from NASA Ames Research Center, Floyd Taylor and Herb Mefford at the University of Kentucky for their assistance in designing and machining many of the components necessary for this project, Zhaojin Diao and Helmut Koch for their help in preparing the measurement campaign, Gregory Gonzales, Joe Wang, Joel Seibert, and Joe Mach for their support at NASA Ames, and Jeff Gragg for his support and cooperation during testing at NASA Langley. 


\section{References}

${ }^{1}$ Schairer, E. T., Heineck, J. T., "Photogrammetric recession measurements of ablative materials in arcjets," Meas. Sci. Technol., 21 025304, 2010.

2 Kontinos, D. A., Stackpoole, M., "Post-Flight Analysis of the Stardust Sample Return Capsule Earth Entry," AIAA 20081197, 46 $6^{\text {th }}$ Aerospace Sciences Meeting, Reno, Jan. 2008

${ }^{3}$ Oishi, T., Martinez, E., "Development and Application of a TPS Ablation Sensor for Flight," 45 th AIAA Aerospace Sciences Meeting and Exhibit, 9-12 January 2008, Reno, NV.

${ }^{4}$ Trumble, K., Cozmuta, I., Sepka, S., Jenniskens, P., Winter, M., "Post-flight Aerothermal Analysis of the Stardust Sample Return Capsule,' Journal of Spacecraft and Rockets, Vol. 47, No. 5, pp. 765-764, Sept.-Oct. 2010.

${ }^{5}$ Winter, M. W., Stackpoole, M., Nawaz, A., Gonzales, G. L., Ho, T., "Remote Recession Sensing of Ablative Heat Shield Materials," $52^{\text {nd }}$ AIAA Aerospace Sciences Meeting, 13 - 17 January 2014, National Harbor, Maryland.

${ }^{6}$ Winter, M. W., McDaniel, R. D., Chen, Y-K., Liu, Y., Saunders, D., Jenniskens, P., "Radiation Modeling for the Reentry of the Hayabusa Sample Return Capsule," AIAA-2012-1296, 50th AIAA Aerospace Sciences Meeting, Nashville, Tennessee, 9 - 12 Jan 2012.

${ }^{7}$ Splinter, S. C., Bey, K. S., Gragg, J. G., Brewer, A., "Comparative Measurements of Earth and Martian Entry Environments in the NASA Langley HYMETS Facility,” AIAA Paper 2011-1014, 49th AIAA Aerospace Sciences Meeting, January 4-7, 2011, Orlando, FL, 2011

${ }^{8}$ Johansen, C., Lincoln, D., Bathel, B., Inman, J., Danehy, P., "Simultaneous Laser-Induced Fluorescence of Nitric Oxide and Atomic Oxygen in the Hypersonic Materials Environment Test System Arcjet Facility," 17th International Symposium on Applications of Laser Techniques to Fluid Mechanics, Lisbon, Portugal, 07-10 July, 2014.

${ }^{9}$ Lachaud, J., Mansour, N. N., Ceballos, A., Pejakovic, D., Zhang, L., Marschall, J.,"Validation of a volume-averaged fiberscale model for the oxidation of a carbon-fiber perform," AIAA-2011-3640, 42 ${ }^{\text {nd }}$ AIAA Thermophysics Conference, 27-30 June 2011, Honolulu, Hawaii. 